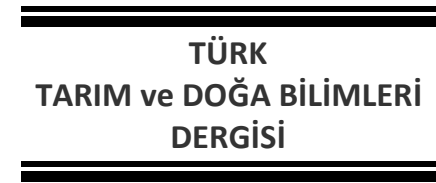

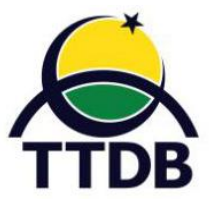

www.dergipark.gov.tr/turkjans

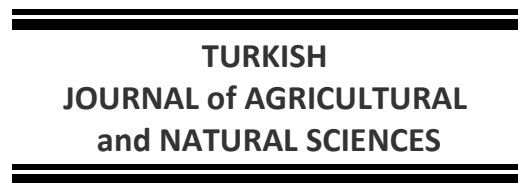

TURKISH

and NATURAL SCIENCES

Araştırma Makalesi

\title{
Farklı Kavuzsuz Arpa (Hordeum vulgare L. var. nudum Hook. f.) Genotiplerinin Illk Gelişme Dönemindeki Bazı Morfolojik Özelliklerinin Belirlenmesi
}

\author{
Soner YÜKSEL ${ }^{1 *}$, Saime ÜNVER IKINCIKARAKAYA² \\ ${ }^{1}$ Geçit Kuşağı Tarımsal Araştırma Enstitüsü, Eskişehir \\ ${ }^{2}$ Ankara Üniversitesi, Ziraat Fakültesi, Tarla Bitkileri Bölümü, Ankara \\ *Sorumlu yazar: soner.yuksel@tarimorman.gov.tr
}

Geliş Tarihi: 07.01.2020 Düzeltme Geliş Tarihi: 09.05.2020 Kabul Tarihi: 14.05.2020

Öz

Bu araştırma; 2012-2013 ve 2013-2014 yetiştirme dönemlerinde Eskişehir'de Geçit Kuşağı Tarımsal Araştırma Enstitüsü’nde yürütülmüştür. Çalışmada son yıllarda ıslahı, üretimi, gıda, yem ve diğer endüstriyel uygulamalarda kullanılmasıyla önem kazanan kavuzsuz arpada bazı hatların ilk gelişme dönemlerindeki özelliklerinin belirlenmesi amaçlanmıştır. Bu amaçla; dokuz adet kavuzsuz arpa hattı ile bir tane tescilli kavuzsuz arpa çeşidi (Özen) kullanılmıştır. Araştırmada kök uzunluğu, fide boyu, fırın kuru kök ve toprak üstü ağırlığı ve bunların birbirine oranları incelenmiştir. İncelenen tüm özellikler yönünden yıllar arası farklılık önemli bulunmuş ve yıllar ayrı ayrı değerlendirilmiştir. Araştırma sonucunda, G1 ve G3 kavuzsuz arpa hatlarının kök uzunluğu, fırın kuru kök / fide oranı diğer genotiplere oranla daha yüksek değerler göstermiştir. Bu hatların kışa dayanıklılık yönünden yapılacak ıslah çalışmalarında değerlendirilebileceği sonucuna varılmıştır. G5 ve G6 nolu hatlar; ilk gelişme döneminde belirlenen özellikler yönünden hatların ortalamasından daha yüksek değerlere sahip olmuştur.G8 kavuzsuz arpa hattı; ilk gelişme döneminde fırın kuru kök ağırlığı ve fırın kuru kök / fide ağırlığı yönünden en yüksek ortalamalara sahip olmuştur. Bu hat devam eden ıslah çalışmaları sonucunda, 2014 yılında Yalın ismi ile tescili gerçekleştirilmiştir. Kavuzsuz arpa genotiplerinde ilk gelişme döneminde önemli farklılıklar saptanmış, hızlı çimlenme ve çıkıs sağlayan genotiplerde; daha iyi bir fide gelişimi ve kök gelişimi tespit edilmiştir.

Anahtar Kelimeler: İlk gelişme dönemi, fide özellikleri, Hordeum vulgare L. var. nudum Hook. f., Islah hattı, kavuzsuz arpa.

\section{Determination of Some Morphological Characteristics of Different Hulless Barley \\ (Hordeum vulgare L. var. nudum Hook. f.) Genotypes in the Early Development Period}

\begin{abstract}
The research was carried out at Transitional Zone Agricultural Research Institute in Eskisehir during the growing seasons of 2012-2013 and 2013-2014. In the study, it was aimed to determine some plant characteristics during the first stages of development of the hulles barley lines of which breeding and production has gained importance in recent years for its use in food, feed and other industrial applications. For this purpose, nine hulless barley lines and one registered variety (Özen) were used. In the research root length, seedling height, oven-dry weights of roots, over ground weight and ratio of oven-dry root weight/oven-dry over ground weight were investigated. The difference between years was found statistically significant in terms of all the features examined and the years were evaluated separately. As a result of the research, in terms of root length and oven-dry root/seedling ratio, hulles barley lines G1 and G3 had higher values than the other genotypes. These lines concluded that it can be evaluated in breeding studies regarding winter resistance. Lines $\mathrm{G} 5$ and $\mathrm{G} 6$ had higher values than mean
\end{abstract}


values of the lines in terms of the characteristics determined in the early development period. Line G8 had the highest mean values regarding oven-dry root weight and oven-dry root/seedling ratio in the early development period. As a result of the ongoing breeding studies, Line G8 was registered in 2014 with the name of Yalın. Significant differences were detected during the first development period of the hulles barley in genotype and beter seedling and root development was identified for the genotypes proving rapid germination and emergence.

Keywords: Early development periods, seedling characteristics, Hordeum vulgare L. var. nudum Hook. f., breeding line, hulles barley.

\section{Giriş}

Arpa (Hordeum vulgare L.) ile buğday (kaplıca) dünyanın en eski kültür bitkilerindendir. Tarih öncesi devirlerde insanlar arpayı besin maddesi olarak kullanmışlardır. Eskiden yaygın olarak insan beslenmesinde kullanılan arpa bugün daha çok hayvan yemi, malt ve bira endüstrisinin hammaddesi olarak kullanılmaktadır. Bugün bile bazı ülkelerde buğday ununa \%8-10 oranında arpa unu karıştırılmaktadır. Genellikle iki sıralı arpalar bira ve malt sanayinde, altı sıralı arpalar ise hayvan yemi üretiminde kullanılmaktadır. Son yıllarda kavuzsuz arpanın ıslahı, üretimi ve gıda, yem ve diğer endüstriyel uygulamalarda kullanılmasıyla ilgili yoğun araştırmalar yapılmaktadır. Kavuzsuz arpa $\beta$-glukan ve diğer besinsel lif kaynakları bakımından zengindir (Yalçın ve ark., 2006).

Arpanın insan gıdası olarak kullanımına olan ilginin son zamanlarda artmasıyla birlikte kavuzsuz arpa önem kazanmaya başlamıştır. Yüksek sindirilebilir protein ve enerji içeriği (Anonim, 1994), ekmek yapımında paçalda kullanılabilmesi, son yıllardaki çalışmalarda ortaya konan $\beta$-glukan içeriği ve yüksek çözünebilir lifler nedeniyle plazma kolestrolünü azaltıcı etkisi kavuzsuz arpaya olan dikkatleri yoğunlaştırmaktadır (Ottekin ve ark., 1996).

Arpa tanesinin buğday tanesinden farkı iç kavuzun taneye sıkıca yapışık olmasıdır. Bu yüzden arpa tanesi kavuzlu tane olarak bilinir. Bunun yanında, kavuzsuz tane veren arpa genotipleri de vardır. Kavuzsuz arpanın sağlık için yararlı olduğu tespit edilen bazı bileşenleri taşıması kavuzsuz arpaya olan ilgileri daha da önemli seviyeye getirmiştir. Ayrıca, kavuzsuz olması öğütme teknolojisi açısından da bazı kolaylıklar getirmektedir. Bilinen klasik buğday ögütme yöntemleri ve ekipmanları ile kepek ve una ayrılabilmektedir (Karaduman, 2006).

Son yillarda artan taleple birlikte ülkemizde kavuzsuz arpa ıslahı konusunda yapılan çalışmalar sonucunda Ankara Tarla Bitkileri Merkez Araştırma Enstitüsü Müdürlüğü (TARM)'ne ait bir hat 2012 yılında ÖZEN ismi ile tescil edilmiştir. Ayrıca 2014 yılında yine aynı enstitü tarafından YALIN ismi ile bir kavuzsuz arpa çeşidi daha tescil ettirilmiştir.

Türkiye'de ıslah ve üretimi konusunda çok fazla çalışma yapılmamış olan kavuzsuz arpanın, insan ve hayvan beslenmesinde önemli bir yer kazanmasıyla birlikte, bu araştırmada; Eskişehir koşullarında bazı kavuzsuz arpa genotiplerinin ilk gelişme dönemlerindeki bazı bitki özelliklerinin belirlenmesi amaçlanmıştır.

\section{Materyal ve Yöntem}

Bu araştırma, 2012-2013 ve 2013-2014 yıllarında, Eskişehir Geçit Kuşağı Tarımsal Araştırma Enstitüsü arazisinde yürütülmüştür. Denemenin kurulduğu alanın denizden yüksekliği $780 \mathrm{~m}$ olup, $30^{\circ} 31^{\prime \prime}$ kuzey enlemleri $39^{\circ} 46^{\prime \prime}$ doğu boylamında yer almaktadır.

Eskişehir ili, batı geçit bölgesinde bulunmasına rağmen ilde karasal iklim görülmektedir. Yıllık yağış miktarı uzun yıllar ortalamasına göre $326.8 \mathrm{~mm}$ 'dir. Denemenin yürütüldüğü 2012-2013 ve 2013-2014 yetiştirme dönemlerine ve uzun yıllara ait aylık sıcaklık ve yağış verileri Çizelge 1 'de verilmiştir (Anonim, 2014). İklim verileri incelendiğinde, yağış açısından iki yıl arasında yaklaşık 45 mm'lik bir fark olduğu görülmektedir. Özellikle birinci yıl başaklanma dönemine rast gelen mayıs ayındaki yetersiz yağış iki yıl arasında iklimsel olarak büyük farklılıklar meydana getirmiştir.

$\mathrm{Bu}$ çalışmada ICARDA (Uluslararası Kurak Alanlarda Tarımsal Araştırma Merkezi) orijinli 9 adet kavuzsuz arpa hattı ile 1 adet tescilli kavuzsuz arpa çeşidi deneme materyali olarak kullanılmıştır. Denemelerde kullanılan kavuzsuz arpa hatlarının genotip melez isimleri Çizelge 2'de verilmiştir. 
Çizelge 1. Deneme yılları ve uzun yıllar ortalamasına ait aylık ortalama sıcaklıklar ve toplam yağış verileri

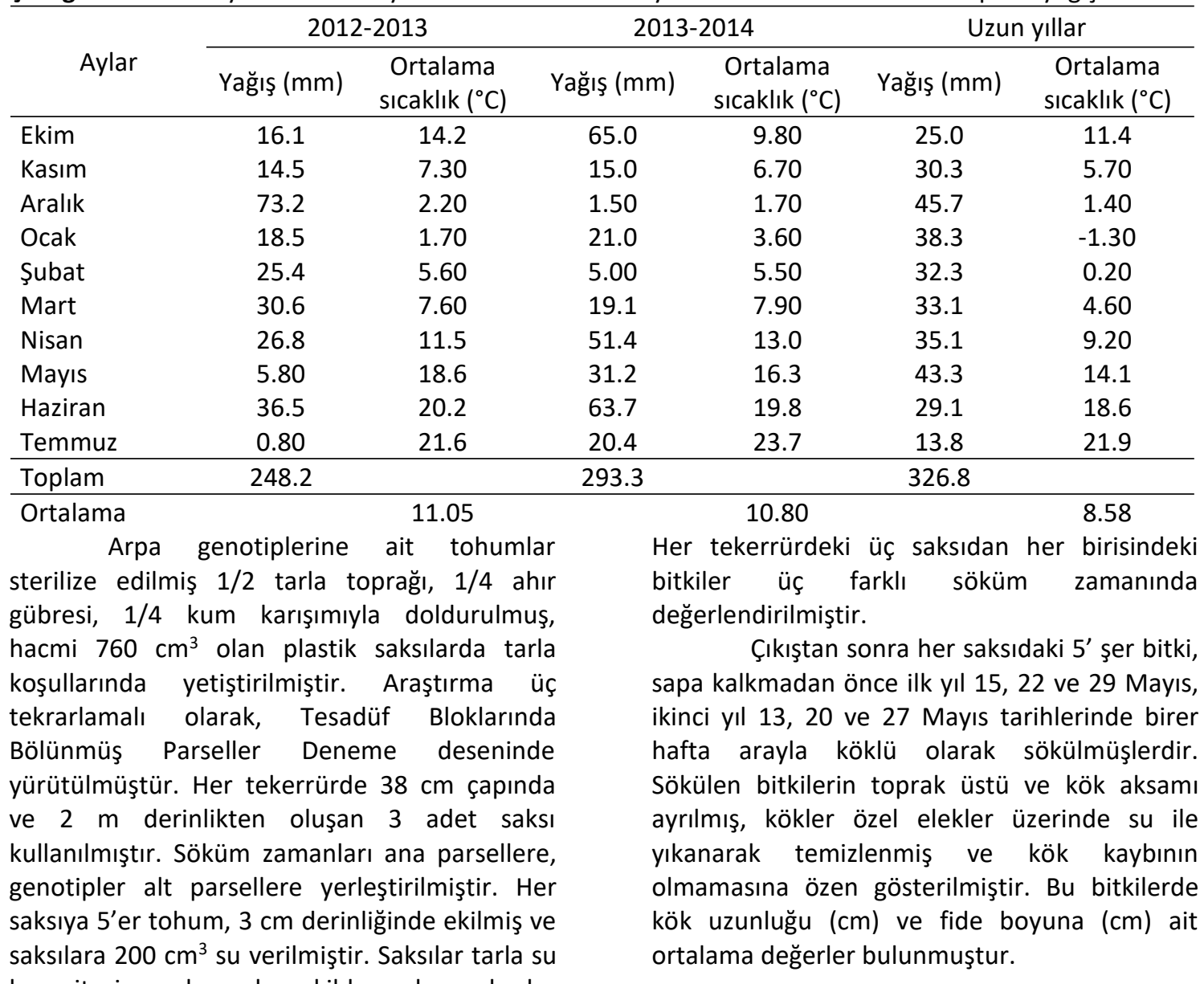
kapasitesine ulaşacak şekilde sulanmışlardır.

Çizelge 2. Araştırmada kullanılan kavuzsuz arpa genotipleri melez ve pedigrileri

\begin{tabular}{cl}
\hline Sıra No & Genotip \\
\hline 1 & Ib90704 \\
2 & Icb100811 \\
3 & Mola/Bermejo"S"//Nispero \\
4 & Icb100819 \\
5 & Bugar \\
6 & K-247/2401-13//Radikal/Vavilon LF7 \\
7 & Roho/Masurka//ICB-103020 \\
8 & Cyclone/4/YAA560.2//Luther/BK259/3/Ngyak-8/Plaisant \\
9 & Cyclone/4/YAA560.2//Luther/BK259/3/Ngyak-8/Plaisant \\
10 & Özen \\
\hline
\end{tabular}

Bu ölçümlerden sonra bitkilerin kök ve toprak üstü kısımları 24 saat oda sıcaklığında kurutulmuştur. Her genotipten beş bitkinin kök ve toprak üstü fırın kuru ağırlıkları $105 \pm 2{ }^{\circ} \mathrm{C}$ sıcaklıkta, ağırlık sabitleşinceye kadar kurutularak bulunmuş, bu değerlerden hesaplama yoluyla kök / toprak üstü oranları belirlenmiştir. Gözlem ve ölçümler Geçit ve ark. (1987)'na göre yapılmıştır. Elde edilen sonuçlar, SAS istatistik programında bölünmüş parsel deneme desenine göre varyans analizine tabii tutulmuştur (SAS Institute 1999). 


\section{Bulgular ve Tartışma}

Kök uzunluğu $(\mathrm{cm})$ : Farklı söküm zamanlarında incelenen kavuzsuz arpa genotiplerinin kök uzunluğuna ilişkin verilerle yapılan varyans analizi sonuçları Çizelge 3'te verilmiştir. Araştırmada ele alınan çeşit ve hatların kök uzunluğuna ilişkin verilerle yapılan varyans analizinde; birinci yılda genotipler arası \%1, söküm zamanı \%5 önemli bulunurken, söküm zamanı $x$ genotip interaksiyonu önemsiz bulunmuştur. İkinci yılda ise, genotipler arası, söküm zamanı ve söküm zamanı $x$ genotip interaksiyonu $\% 1$ düzeyinde önemli bulunmuştur.

Çizelge 3. Farklı söküm zamanlarında kavuzsuz arpa genotiplerinin kök uzunluğuna ait varyans analiz sonuçları

\begin{tabular}{lccc}
\hline V.K. & S.D. & \multicolumn{2}{c}{ K.O. } \\
\cline { 2 - 4 } Genel & & 2013 & - \\
Blok & 89 & 31.81 & 522.04 \\
Söküm zamanı (A) & 2 & $36.57^{*}$ & $1616.54 * *$ \\
Hata & 2014 & 57.95 \\
Genotip (B) & 2 & 3.07 & $119.45^{* *}$ \\
Ax B & 4 & $20.41^{* *}$ & $88.06 * *$ \\
Hata & 9 & 2.87 & 22.40 \\
\hline D.K. (\%) & 18 & 1.82 & 12.39 \\
\hline
\end{tabular}

*: \%5 ve **: \%1 düzeyinde önemli.

Kök uzunluğuna ilişkin ortalamalar ve farklılık gruplandırılması Çizelge 4'de verilmiştir. Çizelge 4 incelendiğinde, söküm zamanlarına göre; arpa genotiplerinin kök uzunluğu ortalamaları arasında önemli farklılıklar olduğu görülmektedir. Kök uzunluğu yönünden en yüksek ortalama, son söküm zamanında 24.46 $\mathrm{cm}$ ile elde edilirken, bunu $23.20 \mathrm{~cm}$ ile ikinci söküm zamanı izlemiş ve en kısa kök uzunluğu birinci söküm zamanında $22.26 \mathrm{~cm}$ olarak belirlenmiştir. Incelenen kavuzsuz arpa genotiplerinin kök uzunlukları göz önüne alındığında, en yüksek kök uzunluğu ortalaması, $25.33 \mathrm{~cm}$ ile G7 hattından elde edilmiştir. G9 hattının kök uzunluğu $25.11 \mathrm{~cm}$ olarak belirlenmiş ve istatistiksel olarak G7 hattı ile aynı grupta yer almıştır. En kısa kök uzunluğu ise $\mathrm{G} 1$ hattından $20.22 \mathrm{~cm}$ ile elde edilmiştir. Çizelge 4'de verildiği gibi, söküm zamanlarına göre, arpa genotiplerinin kök uzunluğu ortalamaları arasında istatistiksel olarak farklılık belirlenmiştir. Üçüncü söküm zamanında G6 arpa hattı $55.83 \mathrm{~cm}$ ile en yüksek kök uzunluğu ortalamasına sahip olurken, en düşük değer G8 arpa hattında birinci söküm zamanında (25.50 $\mathrm{cm}$ ) elde edilmiştir. Üç söküm zamanı ortalamasına göre, genotipler kök uzunluğu yönünden istatistiksel olarak 2 farklı grupta yer almıştır. En yüksek kök uzunluğu ortalaması $(41.73 \mathrm{~cm})$ G5 arpa hattından, en düşük ise $30.27 \mathrm{~cm}$ ile Özen çeşidinden elde edilmiştir. Kök uzunluğuna ait elde edilen bu bulgular, serin iklim tahıllarında kök derinliği üzerine beş yıllık bir çalışmada; buğday kök derinliğinin kardeşlenme öncesinde $30 \mathrm{~cm}$ 'ye kadar, kardeşlenmede 50-60 cm'ye kadar uzadığını bildiren Schliephake ve Garz (1986) ve Geçit ve ark. (1987)'nın bulgularıyla benzerlik göstermektedir. Fide boyu $(\mathrm{cm})$ : Araştırmanın birinci ve ikinci yılında çeşit ve hatların fide boyları incelenmiş ve fide boylarına ait verilerle yapılan varyans analizi sonuçları Çizelge 5'te verilmiştir. Çizelge 5'te görüldüğü gibi, araştırmada kavuzsuz arpa çeşit ve hatların fide boyu uzunluğuna ilişkin verilerle yapılan varyans analizinde; birinci ve ikinci yılda benzer sonuçlar elde edilmiş, genotipler arası, söküm zamanları ve söküm zamanı $x$ genotip interaksiyonu \%1 düzeyinde önemli bulunmuş; kök uzunluğuna ilişkin ortalamalar ve farklılık gruplandırılması Çizelge $6^{\prime}$ da verilmiştir. Üçüncü söküm zamanında G5 numaralı arpa hattı 40.00 $\mathrm{cm}$ ile en yüksek fide boyu ortalamasına sahip olurken, en düşük değer G8 arpa hattında birinci söküm zamanında $(18.00 \mathrm{~cm})$ elde edilmiştir. İkinci söküm zamanında G9 arpa hattı $43.00 \mathrm{~cm}$ ile en yüksek fide boyu ortalamasına sahip olurken, en düşük değer G1 arpa hattında birinci söküm zamanında (19.00 cm) elde edilmiştir. Üç söküm zamanı ortalamasına göre; genotipler fide boyu yönünden istatistiksel olarak 3 farklı grupta yer almıştır. En yüksek fide boyu ortalaması G5 arpa hattından $(34.22 \mathrm{~cm})$, en düşük ise $\mathrm{G} 1$ arpa hattından $(25.55 \mathrm{~cm})$ elde edilmiştir. 
Çizelge 4. Farklı söküm zamanlarında incelenen arpa genotiplerinin 2012-2013 ve 2013-2014 yıllarındaki kök uzunluğuna $(\mathrm{cm})$ ait ortalama değerler

\begin{tabular}{|c|c|c|c|c|c|c|c|c|}
\hline \multirow[b]{2}{*}{ Genotipler } & \multicolumn{4}{|c|}{$2012-2013$} & \multicolumn{3}{|c|}{ 2013-2014 } & \multirow[b]{2}{*}{ Ortalama } \\
\hline & 15 Mayıs & 22 Mayıs & 29 Mayıs & Ortalama & 13 Mayıs & 20 Mayıs & 27 Mayıs & \\
\hline G1 & 20.33 & 19.66 & 20.66 & $20.22^{c *}$ & $37.03^{g-j}$ & $35.83^{g-k}$ & $43.50^{\mathrm{c}-\mathrm{g}}$ & $38.78^{a *}$ \\
\hline $\mathrm{G} 2$ & 21.66 & 24.33 & 25.33 & $23.77^{a b}$ & $33.33^{i-m}$ & $39.16^{f-i}$ & $50.83^{a b c}$ & $41.11^{a}$ \\
\hline G3 & 22.00 & 23.66 & 26.33 & $24.00^{\mathrm{ab}}$ & $32.93^{i-n}$ & $47.33^{\mathrm{b}-\mathrm{e}}$ & $43.00^{\mathrm{d}-\mathrm{g}}$ & $41.08^{a}$ \\
\hline $\mathrm{G} 4$ & 21.33 & 22.33 & 24.00 & $22.55^{b}$ & $32.33^{i-n}$ & $37.50^{g-j}$ & $41.33^{e-h}$ & $37.05^{a}$ \\
\hline G5 & 21.00 & 23.33 & 23.00 & $22.44^{b}$ & $27.70^{\operatorname{lmn}}$ & $45.83^{b-f}$ & $51.66^{a b^{*}}$ & $41.73^{a}$ \\
\hline G6 & 20.33 & 23.66 & 24.00 & $22.66^{b}$ & $27.33^{m n}$ & $41.83^{e-h}$ & $55.83^{a}$ & $41.66^{a}$ \\
\hline G7 & 25.33 & 25.00 & 25.66 & $25.33^{a}$ & $28.00^{\operatorname{lmn}}$ & $35.16^{\mathrm{h}-\mathrm{I}}$ & $43.00^{\mathrm{d}-\mathrm{g}}$ & $35.38^{\mathrm{ab}}$ \\
\hline G8 & 24.66 & 23.00 & 25.00 & $24.22^{a b}$ & $25.50^{n}$ & $31.83^{i-n}$ & $50.33^{a-d}$ & $35.88^{a b}$ \\
\hline G9 & 24.33 & 25.00 & 26.00 & $25.11^{a}$ & $31.00^{j-n}$ & $42.83^{\mathrm{d}-\mathrm{h}}$ & $42.83^{d-h}$ & $38.88^{a}$ \\
\hline Özen & 21.66 & 22.00 & 24.66 & $22.77^{b}$ & $31.50^{i-n}$ & $28.33^{k-n}$ & $31.00^{j-n}$ & $30.27^{b}$ \\
\hline Ortalama & $22.26^{b}$ & $23.20^{\mathrm{ab}}$ & $24.46^{\mathrm{a}}$ & - & $30.66^{b}$ & $38.56^{a}$ & $45.33^{a}$ & - \\
\hline
\end{tabular}

*: Harfler \%5 düzeyinde farklı grupları göstermektedir.

Çizelge 5. Farklı söküm zamanlarında kavuzsuz arpa genotiplerinin fide boyu uzunluğuna ait varyans analiz sonuçları

\begin{tabular}{lccc}
\hline \multirow{2}{*}{ V.K. } & S.D. & $\mathbf{2 0 1 3}$ & $\mathbf{2 0 1 4}$ \\
\cline { 3 - 4 } & & - & - \\
Genel & 89 & 291.67 & 54.97 \\
Blok & 2 & $1064.84^{* *}$ & $1545.91^{* *}$ \\
Söküm zamanı (A) & 2 & 27.99 & 10.24 \\
Hata & 4 & $72.76^{* *}$ & $64.72^{* *}$ \\
Genotip (B) & 9 & $42.79 * *$ & $27.83^{* *}$ \\
A x B & 18 & 11.22 & 3.92 \\
Hata & 54 & 12.20 & 6.24 \\
\hline D.K. (\%) & & &
\end{tabular}

Çizelge 6. Farklı söküm zamanlarında incelenen arpa genotiplerinin 2012-2013 ve 2013-2014 yıllarındaki fide boyuna $(\mathrm{cm})$ ait ortalama değerler

\begin{tabular}{|c|c|c|c|c|c|c|c|c|}
\hline \multirow{2}{*}{ Genotipler } & \multicolumn{4}{|c|}{ 2012-2013 } & \multicolumn{3}{|c|}{ 2013-2014 } & \multirow{2}{*}{ Ortalama } \\
\hline & 13 Mayıs & 20 Mayıs & 27 Mayıs & Ortalama & 15 Mayıs & 22 Mayıs & 29 Mayıs & \\
\hline G1 & $25.00^{g-j}$ & $25.00^{\mathrm{g}-\mathrm{j}}$ & $26.33^{f-i}$ & $25.44^{b c *}$ & $19.00^{k}$ & $28.66^{\mathrm{fgh}}$ & $29.00^{f g h}$ & $25.55^{d *}$ \\
\hline $\mathrm{G} 2$ & $24.67^{g-j}$ & $29.00^{\mathrm{d}-\mathrm{g}}$ & $38.00^{\mathrm{ab}}$ & $30.55^{a}$ & $26.33^{h}$ & $34.33^{e}$ & $39.33^{b}$ & $33.33^{a b}$ \\
\hline G3 & $22.67^{\mathrm{h}-\mathrm{k}}$ & $29.00^{\mathrm{d}-\mathrm{g}}$ & $30.67^{c-f}$ & $27.44^{a b}$ & $22.66^{j}$ & $35.66^{\mathrm{de}}$ & $36.00^{\text {cde }}$ & $31.44^{a b c}$ \\
\hline G4 & $21.00^{\mathrm{ijk}}$ & $32.00^{\text {cde }}$ & $34.00^{\mathrm{bcd}}$ & $29.00^{a b}$ & $27.33^{g h}$ & $37.00^{\mathrm{b}-\mathrm{e}}$ & $36.33^{\mathrm{b}-\mathrm{e}}$ & $33.55^{a b}$ \\
\hline G5 & $19.67^{\mathrm{jk}}$ & $34.00^{\mathrm{bcd}}$ & $40.00^{a}$ & $31.22^{a}$ & $26.00^{\mathrm{hi}}$ & $39.00^{b c}$ & $37.66^{\mathrm{bcd}}$ & $34.22^{a}$ \\
\hline G6 & $18.67^{k}$ & $30.00^{\mathrm{d}-\mathrm{g}}$ & $39.00^{\mathrm{ab}}$ & $29.22^{\mathrm{ab}}$ & $26.66^{h}$ & $37.33^{b c d}$ & $35.00^{\text {de }}$ & $33.00^{\mathrm{ab}}$ \\
\hline G7 & $18.33^{k}$ & $26.00^{f-i}$ & $32.00^{\text {cde }}$ & $25.44^{b c}$ & $22.33^{j}$ & $30.66^{f}$ & $39.33^{b}$ & $30.77^{b c}$ \\
\hline G8 & $18.00^{k}$ & $26.67^{e-h}$ & $35.67^{a b c}$ & $26.77^{a b}$ & $20.00^{\mathrm{jk}}$ & $39.33^{b}$ & $39.00^{b c}$ & $32.77^{a b}$ \\
\hline G9 & $21.33^{h-k}$ & $31.33^{c-f}$ & $30.67^{c-f}$ & $27.77^{a b}$ & $21.00^{\mathrm{jk}}$ & $43.00^{a}$ & $36.66^{\mathrm{b}-\mathrm{e}}$ & $33.55^{a b}$ \\
\hline Özen & $21.33^{h-k}$ & $21.00^{\mathrm{ijk}}$ & $22.33^{\mathrm{h}-\mathrm{k}}$ & $21.55^{c}$ & $23.00^{\mathrm{ij}}$ & $34.00^{e}$ & $30.00^{f g}$ & $29.00^{c}$ \\
\hline Ortalama & $21.06^{b}$ & $28.40^{a}$ & $32.86^{a}$ & & $23.43^{b}$ & $35.90^{a}$ & $35.83^{a}$ & \\
\hline
\end{tabular}

*: Harfler \%5 düzeyinde farklı grupları göstermektedir. 
Kök kuru ağırlığı: Denemenin birinci ve ikinci yılında çeşit ve hatların ilk gelişme dönemleri incelenmiş ve fırın kuru kök ağırlığına ilişkin ortalamalarla yapılan varyans analizi sonuçları Çizelge 7'de verilmiştir. Araştırmada 9 adet kavuzsuz arpa hattı ile 1 adet kavuzsuz arpa çeşidinin fırın kuru kök ağırlığına ilişkin verilerle yapılan varyans analizinde; birinci yılda genotipler arası ve söküm zamanı $\mathrm{x}$ genotip interaksiyonu \%1 önemli bulunurken, söküm zamanı önemsiz bulunmuştur. İkinci yılda ise, genotipler arasında, söküm zamanı ve söküm zamanı $x$ genotip interaksiyonu \%1 düzeyinde önemli bulunmuştur. Fırın kuru kök ağırlığına ilişkin ortalamalar ve farklılık gruplandırılması Çizelge 8'de verilmiştir.

Çizelge 7. Farklı söküm zamanlarında kavuzsuz arpa genotiplerinin kök kuru ağırlığına ait varyans analiz sonuçları

\begin{tabular}{lccc}
\hline \multirow{2}{*}{ V.K. } & S.D. & $\mathbf{2 0 1 3}$ & K.O. \\
\cline { 3 - 4 } & & - & $\mathbf{2 0 1 4}$ \\
\hline Genel & 89 & 0.48 & - \\
Blok & 2 & 0.28 & 0.004 \\
Söküm zamanı (A) & 2 & 0.12 & $1.48^{* *}$ \\
Hata & & $0.29^{* *}$ & 0.004 \\
Genotip (B) & 4 & $0.15^{* *}$ & $0.08^{* *}$ \\
A x B & 9 & 0.05 & $0.04^{* *}$ \\
Hata & 18 & 17.69 & 0.007 \\
\hline D.K. (\%) & 54 & & 13.72 \\
\hline$* * . \% 1$ düzyinde önemli. & & &
\end{tabular}

Çizelge 8. Farklı söküm zamanlarında incelenen arpa genotiplerinin 2012-2013 ve 2013-2014 yıllarındaki fırın kuru kök ağırlığına (g) ait ortalama değerler

\begin{tabular}{|c|c|c|c|c|c|c|c|c|}
\hline \multirow{2}{*}{ Genotipler } & \multicolumn{4}{|c|}{ 2012-2013 } & \multicolumn{3}{|c|}{ 2013-2014 } & \multirow{2}{*}{ Ortalama } \\
\hline & 15 Mayıs & 22 Mayıs & 29 Mayıs & Ortalama & 13 Mayıs & 20 Mayıs & 27 Mayıs & \\
\hline G1 & $1.06^{\mathrm{e}-\mathrm{i}}$ & $0.90^{\text {ghi }}$ & $1.46^{\mathrm{a}-\mathrm{e}}$ & $1.14^{\mathrm{bcd} *}$ & $0.34^{\mathrm{ij}}$ & $0.48^{\text {ghi }}$ & $0.82^{\text {cde }}$ & $0.54^{\text {cde } *}$ \\
\hline $\mathrm{G} 2$ & $1.48^{\mathrm{a}-\mathrm{e}}$ & $1.12^{\mathrm{b}-\mathrm{i}}$ & $1.51^{\mathrm{a}-\mathrm{d}}$ & $1.37^{a b c}$ & $0.49^{g h i}$ & $0.51^{g h}$ & $0.98^{a b}$ & $0.66^{b c}$ \\
\hline G3 & $1.37^{a-f}$ & $1.34^{\mathrm{a}-\mathrm{g}}$ & $1.74^{\mathrm{a}}$ & $1.48^{a}$ & $0.26^{\mathrm{j}}$ & $0.49^{g h i}$ & $0.87^{b-e}$ & $0.54^{\text {de }}$ \\
\hline G4 & $0.98^{f-i}$ & $1.28^{\mathrm{b}-\mathrm{g}}$ & $1.55^{\mathrm{ab}}$ & $1.27^{a-d}$ & $0.30^{j}$ & $0.84^{\mathrm{b}-\mathrm{e}}$ & $0.71^{\text {ef }}$ & $0.61^{\mathrm{b}-\mathrm{e}}$ \\
\hline G5 & $1.47^{\mathrm{a}-\mathrm{e}}$ & $1.31^{\mathrm{a}-\mathrm{g}}$ & $1.54^{\mathrm{abc}}$ & $1.44^{\mathrm{ab}}$ & $0.28^{j}$ & $0.49^{g h i}$ & $0.76^{\text {def }}$ & $0.50^{e}$ \\
\hline G6 & $0.77^{i}$ & $1.28^{\mathrm{b}-\mathrm{g}}$ & $0.92^{\text {ghi }}$ & $0.99^{d}$ & $0.39^{\text {hij }}$ & $0.73^{\text {def }}$ & $0.63^{f g}$ & $0.58^{\text {cde }}$ \\
\hline G7 & $1.10^{\mathrm{c}-\mathrm{i}}$ & $1.01^{f-i}$ & $1.23^{\mathrm{b}-\mathrm{h}}$ & $1.11^{\mathrm{cd}}$ & $0.33^{j}$ & $0.71^{\text {ef }}$ & $0.71^{\text {ef }}$ & $0.58^{\text {cde }}$ \\
\hline G8 & $1.74^{\mathrm{a}}$ & $1.26^{\mathrm{b}-\mathrm{h}}$ & $1.54^{\mathrm{abc}}$ & $1.51^{a}$ & $0.55^{\mathrm{g}}$ & $0.80^{\text {cde }}$ & $0.77^{\text {def }}$ & $0.70^{b}$ \\
\hline G9 & $1.33^{\mathrm{a}-\mathrm{g}}$ & $1.47^{\mathrm{a}-\mathrm{e}}$ & $1.41^{\mathrm{a}-\mathrm{f}}$ & $1.40^{\mathrm{abc}}$ & $0.28^{j}$ & $0.73^{\text {def }}$ & $0.88^{\mathrm{bcd}}$ & $0.62^{b c d}$ \\
\hline Özen & $0.83^{\text {hi }}$ & $1.56^{\mathrm{ab}}$ & $1.08^{\mathrm{d}-\mathrm{i}}$ & $1.16^{\mathrm{bcd}}$ & $0.52^{\mathrm{gh}}$ & $1.05^{a}$ & $0.94^{\mathrm{abc}}$ & $0.84^{a}$ \\
\hline Ortalama & $1.21^{b}$ & $1.25^{b}$ & $1.40^{\mathrm{a}}$ & & $0.37^{b}$ & $0.68^{\mathrm{ab}}$ & $0.80^{\mathrm{a}}$ & \\
\hline
\end{tabular}

*: Harfler \%5 düzeyinde farklı grupları göstermektedir.

Üçüncü söküm zamanında G3 arpa hattı $1.74 \mathrm{~g}$ ile en yüksek fırın kuru kök ağırlığı ortalamasına sahip olurken, en düşük değer G6 arpa hattında birinci söküm zamanında $(0.77 \mathrm{~g})$ elde edilmiştir. En yüksek fırın kuru kök ağırlığı ortalaması G8 arpa hattında $1.51 \mathrm{~g}$ olarak belirlenmiş istatiksel olarak G3 arpa hattı ile aynı grupta yer almıştır. En düşük fırın kuru kök ağırlığı ortalaması G6 arpa hattından (0.99 g) elde edilmiştir. Üç söküm zamanı ortalamasına göre; genotipler fırın kuru kök ağırlığı yönünden istatistiksel olarak 4 farklı grupta yer almıştır. Çizelge 8'de verildiği gibi, fırın kuru kök ağırlığına göre, arpa genotiplerinin ortalamaları arasında istatistiksel olarak farklılık belirlenmiştir. İkinci söküm zamanında Özen kavuzsuz arpa çeşidi 1.05 g ile en yüksek fırın kuru kök ağırlığı ortalamasına sahip olurken, en düşük değer, birinci söküm zamanında G3 arpa hattında (0.26 g) elde edilmiştir. En yüksek fırın kuru kök ağırlığı ortalaması (0.84 g) Özen kavuzsuz arpa çeşidinden, en düşük ise $0.50 \mathrm{~g}$ 
ile G5 arpa hattından elde edilmiştir. Özen kavuzsuz arpa çeşidi genotip özelliğini sonuçlara yansıtarak ilk gelişme devresinde düzenli aralıklarla yapılan sulamadan çok iyi yararlandığı için yoğun bir kök gelişimi göstermiştir. Araştırmada elde edilen bulgular; söküm zamanı ilerledikçe bütün buğday çeşitlerinde fırın kuru kök ağırlığında çeşitlere göre farklı zamanlarda ortaya çıkan belirgin bir artışın olduğunu belirten Geçit ve ark. (1987)'nın bulgularıla benzerlik göstermektedir. Fırın kuru toprak üstü ağırlığı (g): Denemenin birinci ve ikinci yılında çeşit ve hatların ilk gelişme dönemleri incelenmiş ve fırın kuru toprak üstü ağırlığına ilişkin verilerle yapılan varyans analizi sonuçları Çizelge 9'da verilmiştir.

Çizelge 9 incelendiğinde, araştırmada ele alınan 9 adet kavuzsuz arpa hattı ile1 adet kavuzsuz arpa çeşidinin fırın kuru toprak üstü ağırlığına ilişkin verilerle yapılan varyans analizinde; birinci yılda söküm zamanı ve söküm zamanı $x$ genotip interaksiyonu $\% 1$ düzeyinde önemli bulunurken, genotipler arası \%5 düzeyinde önemli olduğu saptanmıştır. İkinci yılda, genotipler arası, söküm zamanları ve söküm zamanı $x$ genotip interaksiyonu $\% 1$ düzeyinde önemli olarak bulunmuştur. Fırın kuru toprak üstü ağırlığına ilişkin ortalamalar ve farklılık gruplandırılması Çizelge 10' da verilmiştir.

Çizelge 9. Farklı söküm zamanlarında kavuzsuz arpa genotiplerinin fırın kuru toprak üstü ağırlığına ait varyans analiz sonuçları

\begin{tabular}{lccc}
\hline \multirow{2}{*}{ V.K. } & S.D. & $\mathbf{2 0 1 3}$ & K.O. \\
\cline { 3 - 4 } & & - & $\mathbf{2 0 1 4}$ \\
\hline Genel & 89 & 0.02 & - \\
Blok & 2 & $3.48^{* *}$ & 0.15 \\
Söküm zamanı (A) & 2 & 0.02 & $0.34^{* *}$ \\
Hata & 4 & $0.03^{*}$ & 0.006 \\
Genotip (B) & 9 & $0.08^{* *}$ & $0.20^{* *}$ \\
A x B & 18 & 0.01 & $0.11^{* *}$ \\
Hata $_{2}$ & 54 & 13.69 & 0.01 \\
\hline D.K. (\%) & & & 15.56 \\
\hline
\end{tabular}

*: \%5 ve **: \%1 düzeyinde önemli.

Çizelge 10. Farklı söküm zamanlarında incelenen arpa genotiplerinin 2012-2013 ve 2013-2014 yıllarındaki fırın kuru toprak üstü ağırlığına (g) ait ortalama değerler

\begin{tabular}{|c|c|c|c|c|c|c|c|c|}
\hline \multirow[b]{2}{*}{ Genotipler } & \multicolumn{4}{|c|}{$2012-2013$} & \multicolumn{3}{|c|}{ 2013-2014 } & \multirow[b]{2}{*}{ Ortalama } \\
\hline & 13 Mayıs & 20 Mayıs & 27 Mayıs & Ortalama & 15 Mayıs & 22 Mayıs & 29 Mayıs & \\
\hline $\mathrm{G} 1$ & $0.61^{h}$ & $1.07^{c-f}$ & $1.01^{\mathrm{efg}}$ & $0.90^{\mathrm{ab}^{*}}$ & $0.48^{m n}$ & $0.45^{n}$ & $0.55^{\operatorname{Imn}}$ & $0.49^{f *}$ \\
\hline $\mathrm{G} 2$ & $0.63^{h}$ & $0.85^{\mathrm{g}}$ & $1.48^{\mathrm{a}}$ & $0.98^{\mathrm{ab}}$ & $1.08^{\mathrm{bc}}$ & $1.06^{\mathrm{bc}}$ & $0.84^{d-h}$ & $0.99^{a}$ \\
\hline G3 & $0.54^{\mathrm{hi}}$ & $0.84^{\mathrm{g}}$ & $1.31^{\mathrm{ab}}$ & $0.89^{\mathrm{ab}}$ & $0.55^{\operatorname{lmn}}$ & $0.70^{h-1}$ & $1.02^{\mathrm{bcd}}$ & $0.76^{\mathrm{cd}}$ \\
\hline G4 & $0.48^{\text {hij }}$ & $1.04^{\mathrm{def}}$ & $1.28^{\mathrm{b}}$ & $0.93^{\mathrm{ab}}$ & $0.80^{f-j}$ & $1.15^{\mathrm{b}}$ & $0.82^{e-i}$ & $0.92^{\mathrm{ab}}$ \\
\hline G5 & $0.31^{j}$ & $1.15^{b-e}$ & $1.07^{c-f}$ & $0.84^{\mathrm{ab}}$ & $0.53^{\operatorname{lmn}}$ & $0.61^{j-n}$ & $1.34^{\mathrm{a}}$ & $0.83^{b c}$ \\
\hline G6 & $0.41^{\mathrm{ij}}$ & $1.01^{\mathrm{efg}}$ & $1.20^{\mathrm{bcd}}$ & $0.87^{a b}$ & $0.52^{\operatorname{lmn}}$ & $0.53^{\operatorname{lmn}}$ & $0.90^{c-g}$ & $0.65^{\text {de }}$ \\
\hline G7 & $0.36^{\mathrm{j}}$ & $0.90^{f g}$ & $1.23^{b c}$ & $0.82^{b}$ & $0.81^{f-i}$ & $0.60^{k-n}$ & $1.00^{b-e}$ & $0.80^{\mathrm{bcd}}$ \\
\hline G8 & $0.62^{h}$ & $0.97^{\mathrm{efg}}$ & $1.48^{\mathrm{a}}$ & $1.02^{\mathrm{a}}$ & $0.71^{\mathrm{h}-1}$ & $0.64^{i-n}$ & $0.79^{f-k}$ & $0.71^{\text {cde }}$ \\
\hline G9 & $0.55^{\mathrm{hi}}$ & $1.07^{c-f}$ & $1.07^{c-f}$ & $0.89^{a b}$ & $0.66^{h-m}$ & $0.63^{i-n}$ & $0.96^{c-f}$ & $0.75^{c d}$ \\
\hline Özen & $0.84^{\mathrm{g}}$ & $0.95^{\mathrm{fg}}$ & $0.93^{f g}$ & $0.90^{\mathrm{ab}}$ & $0.54^{\operatorname{lmn}}$ & $0.75^{g-k}$ & $0.48^{\mathrm{mn}}$ & $0.59^{\mathrm{ef}}$ \\
\hline Ortalama & $0.53^{c}$ & $0.98^{b}$ & $1.20^{\mathrm{a}}$ & & $0.67^{b}$ & $0.71^{b}$ & $0.87^{a}$ & \\
\hline
\end{tabular}

*: Harfler \%5 düzeyinde farklı grupları göstermektedir.

Çizelge 10'da bildirildiği gibi, söküm zamanlarına göre, arpa genotiplerinin fırın kuru toprak üstü ağırlığı ortalamaları arasında istatistiksel olarak farklılık belirlenmiştir. 
Üçüncü söküm zamanında G2 ve G8 arpa hatları $1.48 \mathrm{~g}$ ile en yüksek fırın kuru toprak üstü ağırlığı ortalamasına sahip olmuşlardır. En düşük değer, G5 arpa hattında birinci söküm zamanında $(0.31 \mathrm{~g})$ elde edilmiştir. En yüksek fırın kuru toprak üstü ağırlığı ortalaması G8 arpa hattında 1.02 g olarak belirlenmiştir. En düşük fırın kuru toprak üstü ağırlığı ortalaması G7 arpa hattından (0.82 g) elde edilmiştir.

Fırın kuru toprak üstü ağırlığına göre, arpa genotiplerinin ağırlık ortalamaları arasında istatistiksel olarak farklılık belirlenmiştir. Üçüncü söküm zamanında G5 arpa hattı 1.34 gram ile en yüksek fırın kuru toprak üstü ağırlığı ortalamasına sahip olurken, en düşük değer, ikinci söküm zamanında G1 arpa hattından (0.45 g) elde edilmiştir. Üç söküm zamanı ortalamasına göre; genotipler fırın kuru toprak üstü ağırlığı ortalamaları yönünden istatistiksel olarak 6 farklı grupta yer almıştır. En yüksek fırın kuru toprak üstü ağırlığı ortalaması G2 arpa hattından (0.99 g), en düşük ise $0.49 \mathrm{~g}$ ile G1 arpa hattından elde edilmiştir. Söküm zamanı ilerledikçe, fırın kuru kök ağırlığına benzer şekilde fırın kuru toprak üstü ağırlığında da belirgin bir artış olduğunu ifade eden Geçit ve ark. (1987) ile Lu ve Barber (1985) araştırmamızdan elde ettiğimiz bulguları desteklemektedir.

Fırın kuru kök ağırlığı / fırın kuru toprak üstü ağırlığı oranı: Denemenin birinci ve ikinci yılında çeşit ve hatların ilk gelişme dönemleri incelenmiş ve fırın kuru kök ağırlığının fırın kuru toprak üstü ağırlığı oranına ilişkin verilerle yapılan varyans analizi sonuçları Çizelge 11 'de verilmiştir. Araştırmada ele alınan 9 adet arpa genotipi ile 1 adet arpa çeşidinin fırın kuru kök ağırlığının, fırın kuru toprak üstü ağırlığına oranı hesaplanmış, her iki yıl genotiplere göre istatistiksel olarak \%1 düzeyinde önemli bulunmuştur (Çizelge 11).

Çizelge 11. Farklı söküm zamanlarında incelenen arpa genotiplerinin kök / toprak üstü kuru ağırlığına oranına ilişkin varyans analiz sonuçları

\begin{tabular}{lccc}
\hline \multirow{2}{*}{ V.K. } & S.D. & $\mathbf{2 0 1 3}$ & $\mathbf{2 0 1 4}$ \\
\cline { 3 - 4 } & & & K.O. \\
\hline Genel & 89 & 0.008 & 0.02 \\
Blok & 2 & $0.07^{* *}$ & $0.90^{* *}$ \\
Genotip & 9 & 0.01 & 0.12 \\
Hata & 54 & 15.47 & 19.01 \\
\hline D.K. (\%) & & &
\end{tabular}

**: \%1 düzeyinde önemli.

Çizelge 12. Farklı söküm zamanlarında incelenen arpa genotiplerinin 2013 ve 2014 yıllarındaki kök kuru ağırlığının / toprak üstü kuru ağırlığına oranına ait ortalama değerler

\begin{tabular}{lll}
\hline Genotipler & 2013 & 2014 \\
\hline G1 & $0.60^{\mathrm{bc} *}$ & $2.28^{\mathrm{a} *}$ \\
G3 & $0.69^{\mathrm{bc}}$ & $1.43^{\mathrm{c}}$ \\
G4 & $0.58^{\mathrm{c}}$ & $2.03^{\mathrm{ab}}$ \\
G5 & $0.68^{\mathrm{bc}}$ & $1.41^{\mathrm{c}}$ \\
G6 & $0.70^{\mathrm{bc}}$ & $2.04^{\mathrm{ab}}$ \\
G7 & $0.73^{\mathrm{bc}}$ & $1.65^{\mathrm{bc}}$ \\
G8 & $0.76^{\mathrm{b}}$ & $1.46^{\mathrm{c}}$ \\
G9 & $0.75^{\mathrm{b}}$ & $2.12^{\mathrm{ab}}$ \\
Özen & $0.66^{\mathrm{bc}}$ & $1.92^{\mathrm{ab}}$ \\
\hline
\end{tabular}

*: Harfler \%1 düzeyinde farklı grupları göstermektedir.

Birinci yıl genotiplere ait söküm zamanları ortalaması olarak ele alınan fırın kuru kök ağırığının, fırın kuru toprak üstü ağırlığı oranına ait ortalama değerler ve farklılık gruplandırılması Çizelge 12'de verilmiştir.
Ortalamaların farklılık gruplandırması incelendiğinde; birinci yıl 0.92 oran ile Özen çeşidi en yüksek, 0.58 ile G3 arpa hattı en düşük fırın kuru kök ağırlığının fırın kuru toprak üstü ağırlığına oranına sahip genotip ve çeşit olmuşlardır. Genotipler, fırın kuru kök 
ağırlığının fırın kuru toprak üstü ağırlığına oranı yönünden istatistiksel olarak 3 farklı grupta yer almıştır. İkinci yıl G1 numaralı arpa hattı (2.28) en yüksek fırın kuru kök ağırlığının fırın kuru toprak üstü ağırlığına oranına sahip iken G4 numaralı hat (1.41) en düşük ağırlığa sahip olmuştur.

Kök / toprak üstü ağırlık oranının düşük olması, toprak üstü gelişmesinin köke göre daha fazla olduğunu göstermekte, kök gelişiminin az, toprak üstü gelişiminin fazla olması kurağa dayanıklıı̆̆ın azalmasına neden olmaktadır (Geçit ve ark., 1987).

Araştırmamızda elde ettiğimiz bulgular, Sadhu ve Bhaduri (1983), Joubert (1984), Lu ve Barber (1985), Schliephake ve Garz (1986), Kuz'min ve Shumeiko (1987), Geçit ve ark. (1987)'nın bulgularıla benzerlik göstermektedir.

\section{Sonuç ve Öneriler}

Araştırma sonuçlarına göre, incelenen kavuzsuz arpa genotiplerinin kök ve toprak üstü organlarının gelişme durumları arasında önemli farklılıklar belirlenmiştir. Kavuzsuz arpa genotiplerinin ilk gelişme döneminde önemli farklılıklar saptanmış, hızlı çimlenme ve çıkış sağlayan genotiplerde; daha iyi bir fide gelişimi ve kök gelişimi tespit edilmiştir.

Kök uzunluğu, fırın kuru kök / fide oranı diğer genotiplere oranla daha yüksek değer gösteren G1 kavuzsuz arpa hattı kısa boylu olması ve sağlam bir sapa sahip olması yönüyle kışa dayanıklılık yönünden yapılacak ıslah çalışmalarında değerlendirilebileceği sonucuna varılmıştır.

G8 kavuzsuz arpa hattı; ilk gelişme döneminde fırın kuru kök ağırlığı ve fırın kuru kök/fide ağırlığı yönünden en yüksek ortalamalara sahip olmuştur. Bu hattın devam eden ıslah çalışmaları sonucunda, 2014 yılında Yalın ismi ile tescili gerçekleştirilmiştir. Yalın kavuzsuz arpa çeşidi, kışlık gelişme özelliğinde olan bir çeşittir.

Tescilli çeşit olan Özen ise yazlık özelliği ile öne çıkmış ve ilk gelişme döneminde deneme ortalamasına yakın değerler elde edilmiştir.

*: Doktora tezinden derlenmiştir.

\section{Kaynaklar}

Anonim, 2014. Aylık Hava Raporu Verileri. Orman ve Su İşleri Bakanlığı, Meteoroloji 3. Bölge Müdürlüğü, Eskişehir
Anonymous, 1994. Cereal Programme, ICARDA Annual Report 172 pp, Aleppo/Syrı.

Geçit, H.H., Emeklier, H.Y., Çiftçi, C.Y., Ünver, S., Şenay, A. 1987. Ekmeklik Buğdayda Illk Gelişme Devresinde Kök ve Topraküstü Organlarının Durumu. Türkiye Tahıl Simpozyumu, 6-9 Ekim 1987; Bursa.

Joubert, G.D. 1984. Root development of different wheat cultivars. Field crop. Abst. Vol. 37, 556-565.

Karaduman, Y. 2006. Kavuzsuz Arpa Potansiyeli. Unlu Mamuller Tek. Dergisi 74: 21-26.

Kuz'min, N.A., Shumeiko, A.F. 1987. The root system of spring wheat and possibility of improving varietes by strengthening its development. Field Crop. Abst. Vol. 40, (62).

Lu, N. and Barber, S.A. 1985. Phosphorus uptake rate and growth charecteristic of wheat roots. Field Crop. Abst. Vol. 39, (368).

Ottekin, A., Akar, T., Tosun, H., Ozan, A.N. Demir, Z. 1996. Kavuzsuz Arpanın Tarımsal ve Teknolojik Özelliklerinin Belirlenmesi. IV. Ulusal Nükleer Tarım ve Hayvancılık Kongresi. Tebliğ Özetleri,(29); Bursa.

Sadhu, D., Bhaduri, P.N. 1983.Variable traits of root and shoot of wheat under embryo cultural conditions. Zeitschrift für Ackerundpflenzenbau, 152 (5); 381-388.

SAS Institute (1999). SAS/STAT User's Guide. SAS Inst. Inc. Cary. NC

Schliephake, W., Garz, J. 1986. Rooting depth of winter cereals during development until ear emergence. Archiv Acker-und Pflenzenbau und Bodenkunde, 30 (7); 447-453.

Yalçın, E., Çelik, S., Akar, T., Sayım, I., Köksel, H. 2006. Kavuzsuz arpanın önemi, $\beta$-glukan ve besinsel lif içeriği. Hububat Ürünleri Teknolojisi Kongresi.7-8 Eylül 2006, (399-403); Gaziantep. 